\title{
Herpetic inflammation of multiple cranial nerves
}

\author{
Kamyar Ghabili • Mohammadali M. Shoja • \\ R. Shane Tubbs • Aaron A. Cohen-Gadol
}

Received: 11 January 2009/Accepted: 14 December 2009/Published online: 30 January 2010

(C) Springer-Verlag 2010

\section{Dear Editor,}

We read with great interest the paper of Morelli et al. [1] which described a patient with varicella-zoster reactivation from multiple unilateral cranial ganglia and/or nerves. This report is quite interesting as, to the best of our knowledge, such extensive involvement of cranial nerves V, VII, VIII, IX, X, XI and XII has not been previously reported. The authors referred to this condition as Ramsay-Hunt syndrome. We believe that referring to the above condition as Ramsay-Hunt syndrome is a misnomer as the classic Ramsay-Hunt syndrome did not include features of inflammation in the cranial nerves V, XI and XII. As a matter of fact, Hunt's original description of 1907 [2] only included the inflammation of sensory ganglia of the cranial nerves VII, VIII, IX and X (as cited in reference [3]). In general, Sharpe in 1915 [3] classified the herpes zoster cephalicus into five categories based on the pattern of

K. Ghabili ( $\square)$

Tuberculosis and Lung Diseases Research Center,

Tabriz University of Medical Sciences,

Golgasht St., Tabriz, Iran

e-mail:kghabili@gmail.com

M. M. Shoja - A. A. Cohen-Gadol

Indianapolis Neurosurgical Group,

Clarian Neuroscience Institute,

Indianapolis, IN, USA

M. M. Shoja - A. A. Cohen-Gadol

Department of Neurosurgery,

Indiana University, Indianapolis, IN, USA

R. S. Tubbs

Section of Pediatric Neurosurgery,

Children's Hospital, Birmingham, AL, USA nerve affections: inflammation of the geniculate ganglia; inflammation of the geniculate ganglia with facial palsy and acoustic symptoms; inflammation of the auditory ganglia; inflammation of the glossopharyngeal and vagal ganglia; and herpes zoster facialis or occipitocollaris with facial palsy and/or auditory symptoms.

In conclusion, we believe that Ramsay-Hunt syndrome only represents a subgroup of "herpetic inflammation of multiple cranial nerves". This also may be complicated by cervical nerve involvement as well $[4,5]$. Hence, it is clear that a variety of clinical pictures far exceeding RamsayHunt syndrome can be seen in herpes zoster cephalicus.

\section{References}

1. Morelli N, Mancuso M, Cafforio G et al (2008) Ramsay-Hunt syndrome complicated by unilateral multiple cranial nerve palsies. Neurol Sci 29:497-498

2. Hunt JR (1907) On herpetic inflammations of the geniculate ganglion: a new syndrome and its complications. J Nerv Ment Dis 34:73-96

3. Sharpe N (1915) Herpes zoster of the cephalic extremity, with a special reference to the geniculate, auditory, glossopharyngeal and vagal syndromes. Am J Med Sci 149:725-737

4. Kin T, Hirano M, Tonomura $\mathrm{Y}$ et al (2006) Coexistence of Ramsay-Hunt syndrome and varicella-zoster virus encephalitis. Infection 34:352-354

5. Hashemilar M, Ghabili K, Shoja MM et al (2009) Varicella-zoster virus reactivation from multiple ganglia: a case report. J Med Case Reports 3:9134 